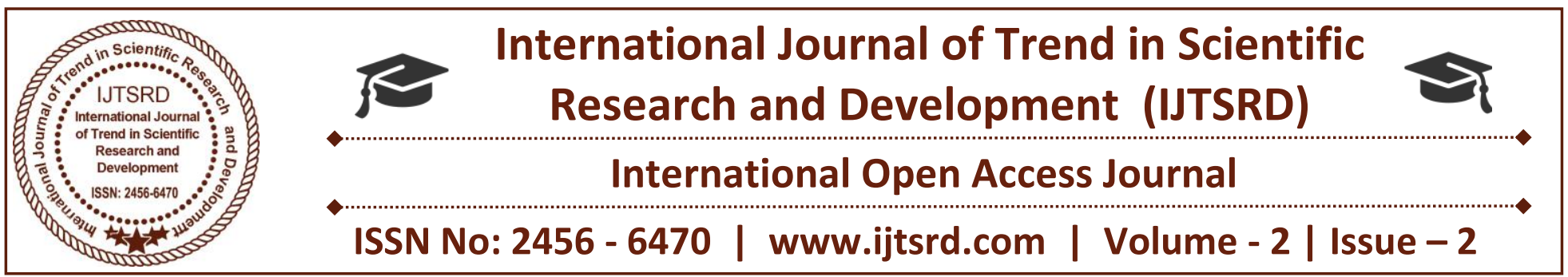

\title{
Study on effect of Polypropylene and Steel Fiber on the strength of Concrete
}

\author{
Akanksha Agrawal \\ Assistant Professor, Civil Engineering Department, \\ Bhivrabai Sawant College of Engineering and \\ Research Engineering, Narhe, Pune, India
}

\section{ABSTRACT}

Concrete is most widely used material in the construction as it is relatively strong in compression but weak in tension and tends to be brittle. These two weaknesses have limited its use. Fiber reinforced concrete is most widely used for improving tensile and flexural strength of concrete. In this paper an attempt has been made to explore the effects of polypropylene fiber on some hardened properties of PFRC based on its compressive strength, flexural strength and flow ability. In this research, concrete mixes were added with polypropylene fiber of $0 \%$, $0.2 \%, 0.4 \%$, and $0.8 \%$ volume fraction and Steel Fibers were added in a varying dose of $0 \%, 0.2 \%$, $0.4 \%$, and $0.8 \%$. An experimental result demonstrated a notable increase in flexural, tensile strength was found. However, no significant change in compression strength is observed.

Keywords: Fiber Reinforced Concrete, Flexural strength, Polypropylene Fiber

\section{Introduction}

Concrete is a tension-weak building material and possess low resistance to the cracking. Also their tensile strength and flexural strength is relatively low compared to their compressive strength. To improve such properties, Fiber reinforced concrete (FRC) has been developed (Banthia N and Sheng J.,1996).The reinforcing fibers are randomly distributed in the matrix. The addition of the fibers enhances the engineering properties of concrete like Flexural strength, Compressive strength, ductility and toughness. The concrete-reinforcing fibers include metal, polymer, glass, asbestos and various others. Among the polymer fibers, the polypropylene fibers enjoy popularity in the domain of concrete. The common forms of polypropylene fibers are smoothmonofilament and have triangular shape. These fibers have low density and are chemically inert and non corrosive. It was reported that application of polypropylene fibers improves the plain concrete properties including splitting tensile strength, first crack strength and impact resistance (Song P.S,.Hwang.S., andSheu.B.S.,2005)

Alhozaimy et al.observed that an additional amount of $0.1 \%$ polypropylene fibers in the plan concrete had 44 $\%$ increases in flexural toughness of the concrete.

(Preeti A Patel \& Arun k Desai.,2012) concluded that the polypropylene fibers do not disperse properly in the mixing water therefore the addition of the fibers to dry mix was found to be more practical. Also in the plain concrete the failure was due to the spalling however the failure mode in the fiber reinforced concrete is due to the bulging in the transverse direction. [Arkan RAdi Ali 2013] demonstrated that the addition of fibers reduces the workability and the slump value. Effect of polypropylene fibers was more dominant in the tension as compared to the compression due to the adhesive and friction forces between the polypropylene fibers and the concrete. 
International Journal of Trend in Scientific Research and Development (IJTSRD) ISSN: 2456-6470

\subsection{Material and Methods}

\subsection{Cement}

Ordinary Portland cement of 43 grade having 28 days compressive strength $57.5 \mathrm{~N} / \mathrm{mm} 2$ satisfying the requirement of IS: 8112-2013. The specific gravity of the cement was found to be 3.13. The physical and chemical properties if the Cement are as given in the table 1 .

\section{Table 1}

\begin{tabular}{|c|l|l|}
\hline S. No. & Test & Value \\
\hline 1 & Specific Gravity & 3.13 \\
\hline 2 & Soundness & $1 \mathrm{~mm}$ \\
\hline 3 & Standard Consistency & $28 \%$ \\
\hline 4 & Initial setting Time & $145 \mathrm{~min}$ \\
\hline 5 & Final Setting time & $240 \mathrm{~min}$ \\
\hline 6 & Compressive Strength & 38.5 \\
\cline { 2 - 3 } & 3 days & $\mathrm{N} / \mathrm{mm} 2$ \\
\cline { 2 - 3 } & 7 days & 50.5 \\
\cline { 2 - 3 } & 28 days & N/mm2 \\
& & $\mathrm{N} / \mathrm{mm} 2$ \\
\hline
\end{tabular}

\subsection{Fine Aggregate}

The sand was collected from the Mahanadi River bed. The material passing through $4.75 \mathrm{~mm}$ IS sieve, grade Zone II conforming the IS: $383-1970$ was used. The physical properties of the sand are given in the table 2.

\section{Table 2}

\begin{tabular}{|l|l|l|}
\hline $\begin{array}{l}\text { S. } \\
\text { No. }\end{array}$ & Physical Properties & Value \\
\hline 1 & Specific Gravity & 2.63 \\
\hline 2 & Fitness Modulus & 2.55 \\
\hline 3 & $\begin{array}{l}\text { Bulk density Dry Roded } \\
\text { (DRD) }\end{array}$ & 1.628 \\
\hline 4 & Loose Bulk Density & 1.59 \\
\hline
\end{tabular}

\subsection{Coarse Aggregate}

Mechanically crushed limestone with $20 \mathrm{~mm}$ as maximum size satisfying IS: $383-1970$ was used. The physical properties of the coarse aggregate are given in the table 3 .
Table 3:

\begin{tabular}{|l|l|l|l|}
\hline $\begin{array}{l}\text { S. } \\
\text { No. }\end{array}$ & $\begin{array}{l}\text { Physical } \\
\text { Properties }\end{array}$ & $\begin{array}{l}\text { Value } \\
\mathbf{1 0} \mathrm{mm}\end{array}$ & $\begin{array}{l}\text { Value } \\
\mathbf{2 0} \mathrm{mm}\end{array}$ \\
\hline 1 & Specific Gravity & 2.174 & 2.743 \\
\hline 2 & Fitness Modulus & 1.55 & 1.35 \\
\hline 3 & $\begin{array}{l}\text { Bulk density Dry } \\
\text { Roded (DRD) }\end{array}$ & 1.551 & 1.549 \\
\hline 4 & $\begin{array}{l}\text { Loose Bulk } \\
\text { Density }\end{array}$ & 1.422 & 1.456 \\
\hline
\end{tabular}

\subsection{Chemical Admixture}

Plasticizer CAC-Super flow $35 \mathrm{U}$ admixture was used having the specific gravity 1.2 .

\subsection{Polypropylene Fibers}

Polypropylene Fibers were used in this study .Various properties of the Polypropylene Fibers are as given in the Table 4.

\begin{tabular}{|l|l|}
\hline \multicolumn{2}{|c|}{ Table 4: } \\
\hline Material & polypropylene \\
\hline Relative Density & 0.91 \\
\hline Length & $12 \mathrm{~mm}$ to $19 \mathrm{~mm}$ \\
\hline Width & $0.91 \mathrm{~mm}$ \\
\hline Electrical Conductivity & Low \\
\hline
\end{tabular}

\subsection{Steel Fibers}

\begin{tabular}{|l|l|}
\hline Material & Steel \\
\hline Length & $36 \mathrm{~mm}$ \\
\hline Effective Diameter & $0.6 \mathrm{~mm}$ \\
\hline Tensile Strength & $1100 \mathrm{Mpa}$ \\
\hline
\end{tabular}

\subsection{Concrete Mix Proportion}

Concrete mix proportion and the properties of the concrete used in this study are as given in the table 5 . The fiber volume fraction was varied as $0 \%, 0.2 \%$, $0.4 \%$, and $0.8 \%$. The mixtures were proportioned based on the water cement ratio (w/c) 0.55 . and fine to coarse aggregate ratio $(\mathrm{F} / \mathrm{C})$ as 0.78 . From each mixture nine cubes $(150 \times 150 \times 150 \mathrm{~mm})$ specimens are casted. Fresh concrete mixture in the moulds is compacted using table vibrator. After casting the specimens were demoulded and water cured at room temperature until the age of testing at 3,7 and 28 days. Specimens are tested at 3days, 7 days and 28 days. 
International Journal of Trend in Scientific Research and Development (IJTSRD) ISSN: 2456-6470

Table 6: Concrete Mix Design

\begin{tabular}{|l|l|}
\hline Content & Quantity \\
\hline Cement $(\mathrm{kg} / \mathrm{m} 3)$ & 300 \\
\hline FlyAsh $(\mathrm{kg} / \mathrm{m} 3)$ & 140 \\
\hline Fine Aggregate $(\mathrm{kg} / \mathrm{m} 3)$ & 793 \\
\hline Coarse Aggregate $(\mathrm{kg} / \mathrm{m} 3)$ & 1021 \\
\hline Water Content $(\mathrm{kg} / \mathrm{m} 3)$ & 167 \\
\hline F/C & 0.78 \\
\hline W/B & 0.38 \\
\hline
\end{tabular}

For all mix proportions these components are kept constant while the dosages of polypropylene fibers are Steel Fibers are varied. This can be seen in Table 7 and Table 8.

Table 7: Dose of polypropylene Fiber

\begin{tabular}{|c|c|}
\hline MIX ID & Polypropylene Fiber (\%) \\
\hline M1 & $0 \%$ \\
\hline M2 & $0.2 \%$ \\
\hline M3 & $0.4 \%$ \\
\hline M4 & $0.6 \%$ \\
\hline M5 & $0.8 \%$ f Trentriand Trend \\
\hline
\end{tabular}

Table 8: Dose of Steel Fiber

\begin{tabular}{|c|c|}
\hline MIX ID & Steel \\
\hline A1 & $0 \%$ \\
\hline A2 & $0.2 \%$ \\
\hline A3 & $0.4 \%$ \\
\hline A4 & $0.6 \%$ \\
\hline A5 & $0.8 \%$ \\
\hline
\end{tabular}

\subsection{Experimental Test Result and Discussion}

\subsection{Properties of Fresh Concrete}

Effect of addition of polypropylene fiber on the fresh concrete is measured in terms of slump value of the concrete.

Result indicates that the workability reduces at higher dosage of the fibers as compared to the initial dosage. This is because of increase in the air content due to presence of fibers and thus reduces the workability. Result shows that at controlled concrete and at $0.2 \%$ and $0.4 \%$ of fiber content the workability is high However for the dose of $0.6 \%$ it is medium.

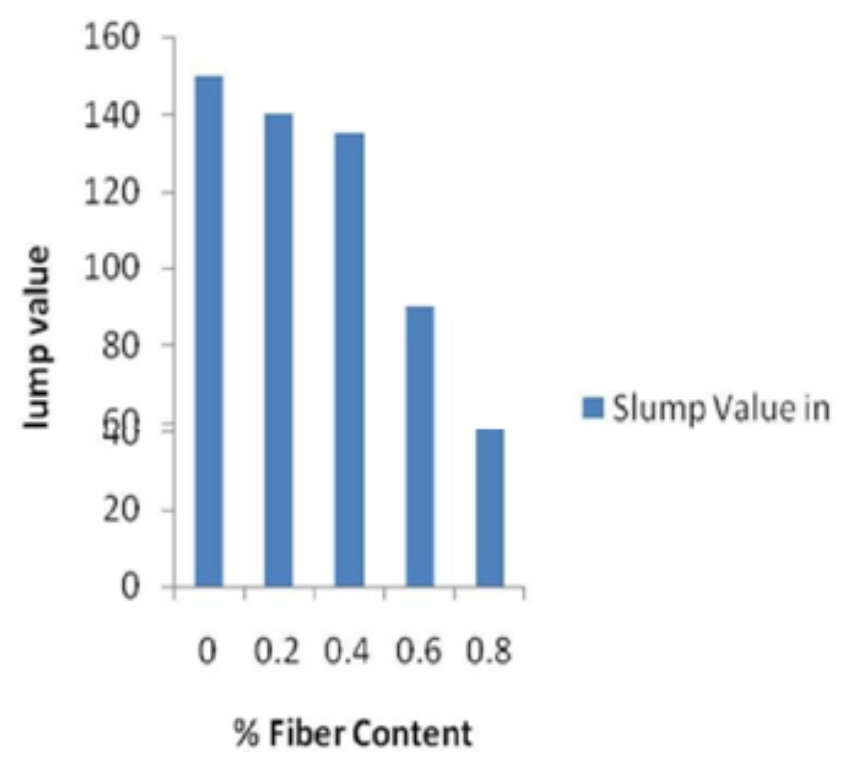

Figure1: Slump value at different dose of polypropylene Fiber

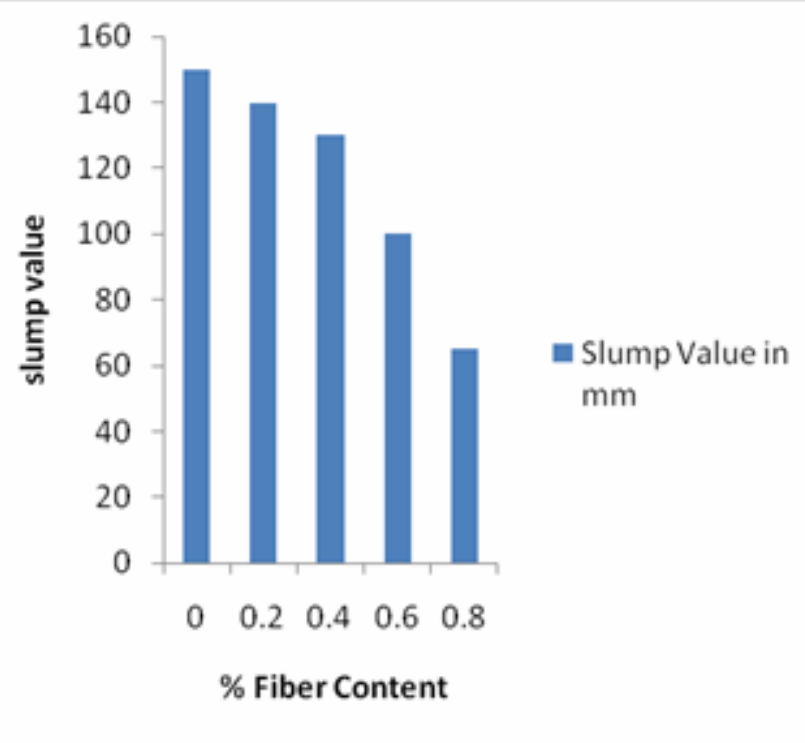

Figure2: Slump value at different dose of Steel Fiber

\subsection{Effect on the Compressive strength}

The test result for the various mixes on the cube specimens at the age of 3, 7 and 28 days in the compression testing machine are shown graphically in the figure 2 and 3 . The compressive strength interpreted by stress generated from the result of compression load per area of specimen surface. The results for each specimen are based on an average value of three replicate specimens. The result shows that the inclusion of the fibers does not improve the compressive strengths significantly. 


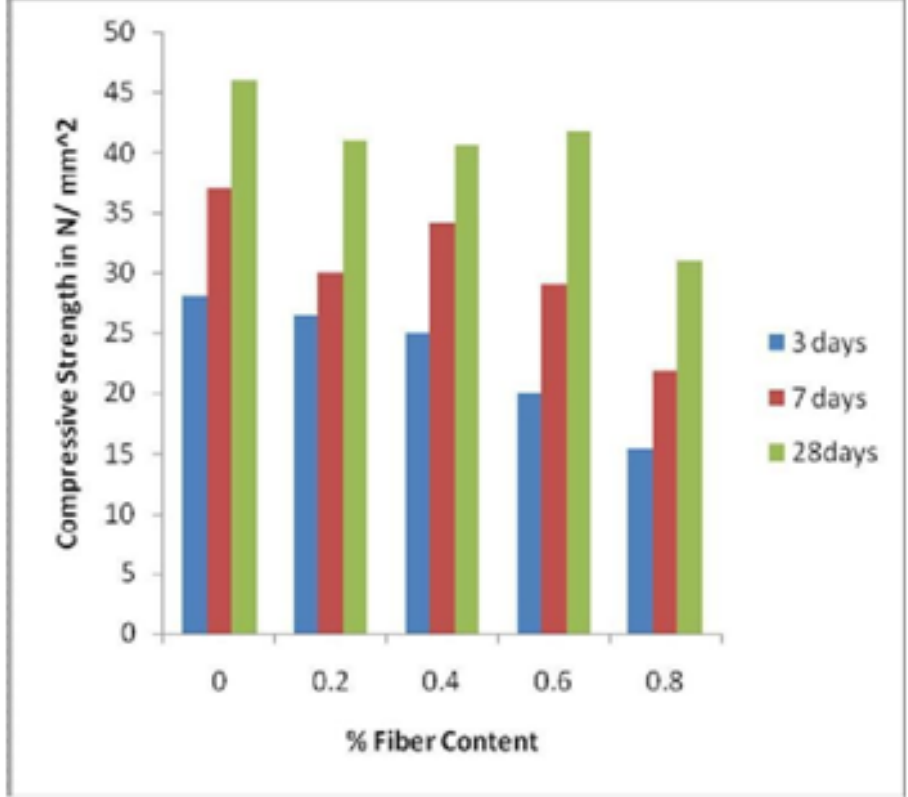

Figure 3: Compressive strength at different dose of Polypropylene Fiber

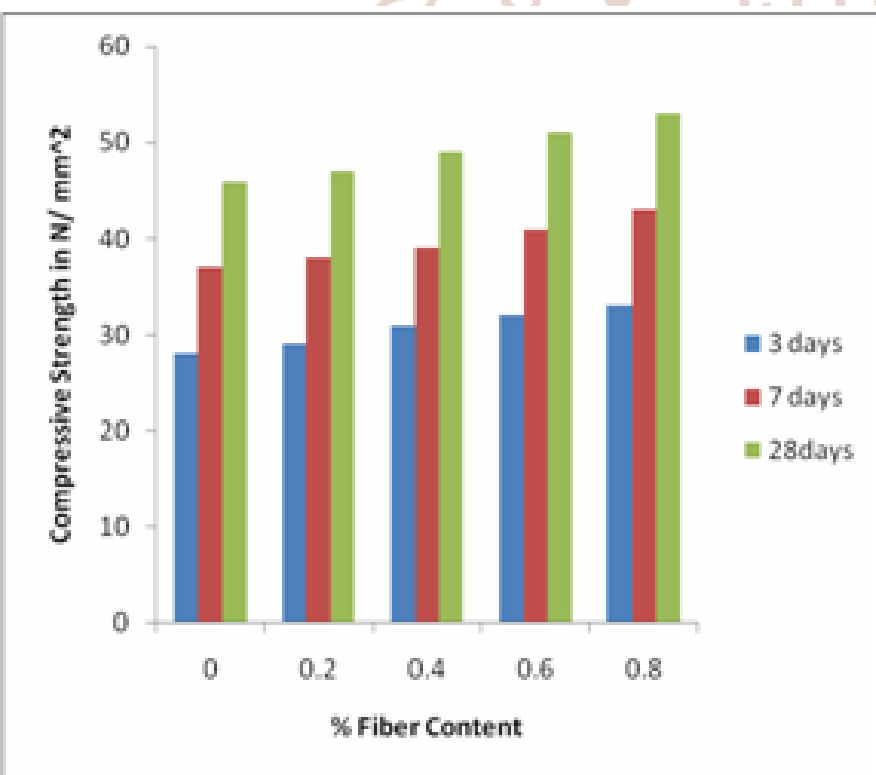

Figure 4: Compressive strength at different dose of Steel Fiber

\subsection{Effect on the Flexural Strength}

Flexural strength at 28 days of curing test was conducted according to the requirements of IS 516 using three $150 \times 150 \times 700 \mathrm{~mm}$ beams under thirdpoint loading on a simply supported span of $600 \mathrm{~mm}$. The flexural strength of the mix at $0.4 \%$ and $0.6 \%$ increases by $26.67 \%$ and $45.77 \%$ respectively at 7 days and $36.23 \%$ and $40 \%$ respectively for 28days as compared to the controlled concrete. The enhancement in the flexural strength is due to the increase in the bond strength between the cement paste and the fibers. The increase in the fiber content also reduces the crack widening. Figure 5 and 6 shows the graphical representation of the flexural strength at 7 and 28 days respectively.

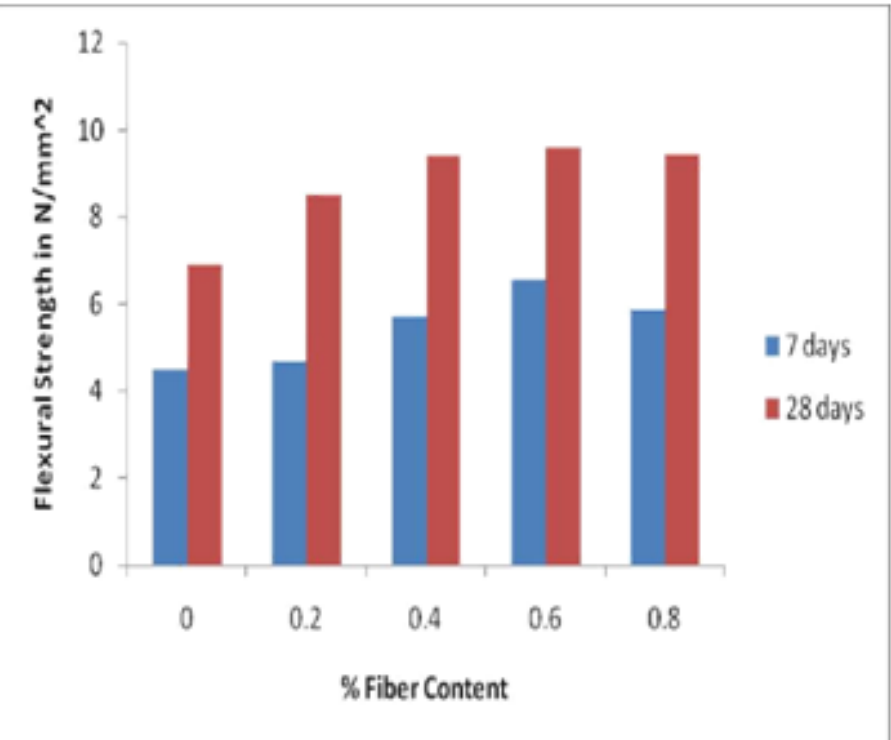

Figure 5: Flexural strength at different dose of polypropyelene Fiber

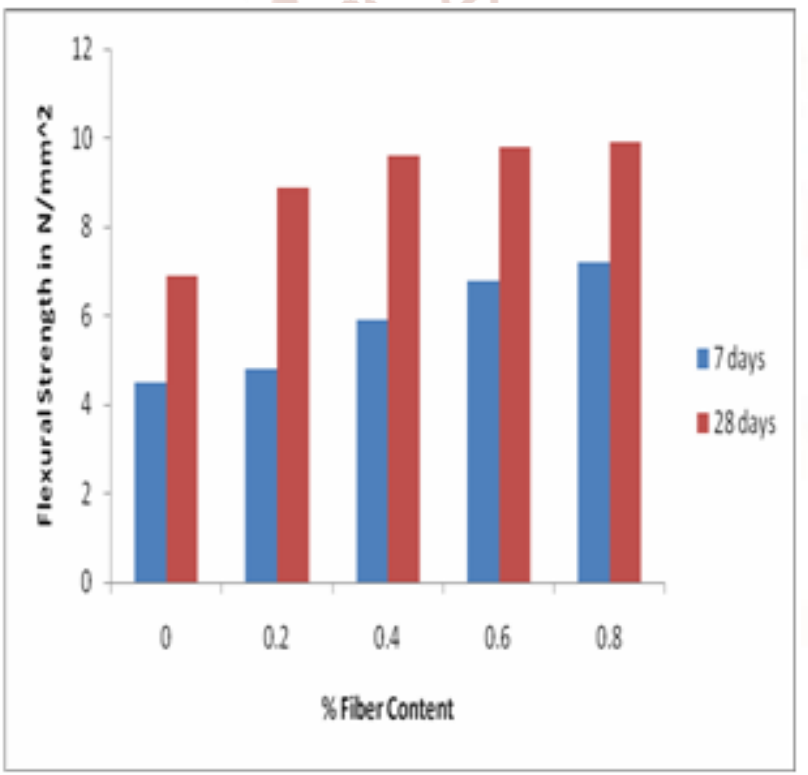

Figure 6: Flexural strength at different dose of Steel Fiber

\subsection{Effect on the Split Tensile Strength}

The split tensile strength varies from $2.95 \mathrm{~N} / \mathrm{mm} 2$ to $5.85 \mathrm{~N} / \mathrm{mm}^{2}$ for 7 days and $7.25 \mathrm{~N} / \mathrm{mm}^{2}$ to 8.55 $\mathrm{N} / \mathrm{mm}^{2}$ for 28 days. The result indicates that there is maximum gain of $17 \%$ in the split tensile strength at 28 days. Once the splitting occurred and continued, the fibers bridging across the split portions of the 

matrix acted through the stress transfer from the matrix to the fibers and this stress transfer improved the tensile strain capacity. Fiber bridging mechanism is mainly responsible for the increase in the strength.

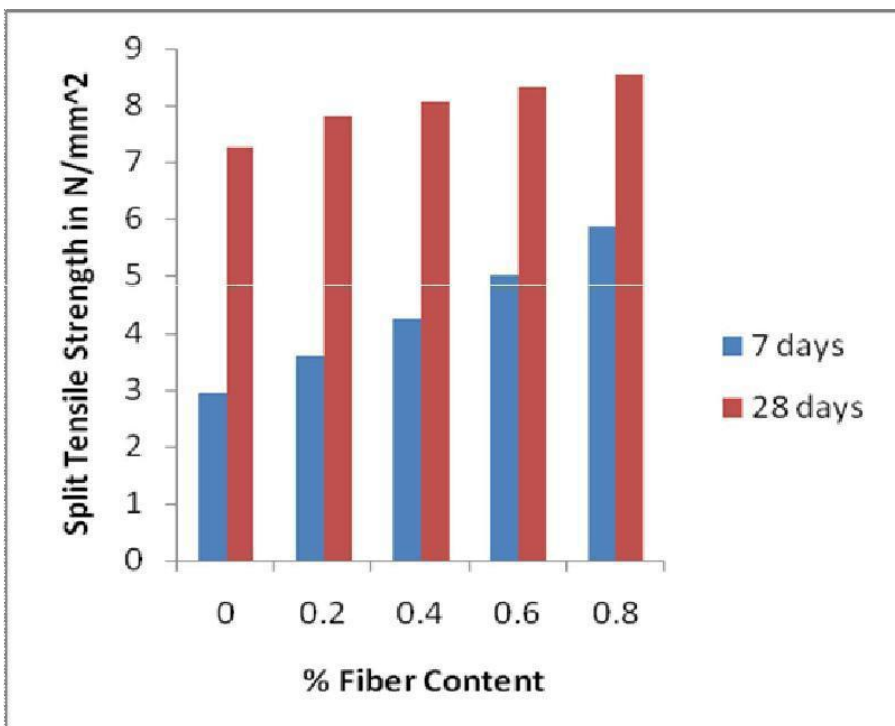

Figure 7: Split Tensile strength at different Dose of polypropylene Fiber content

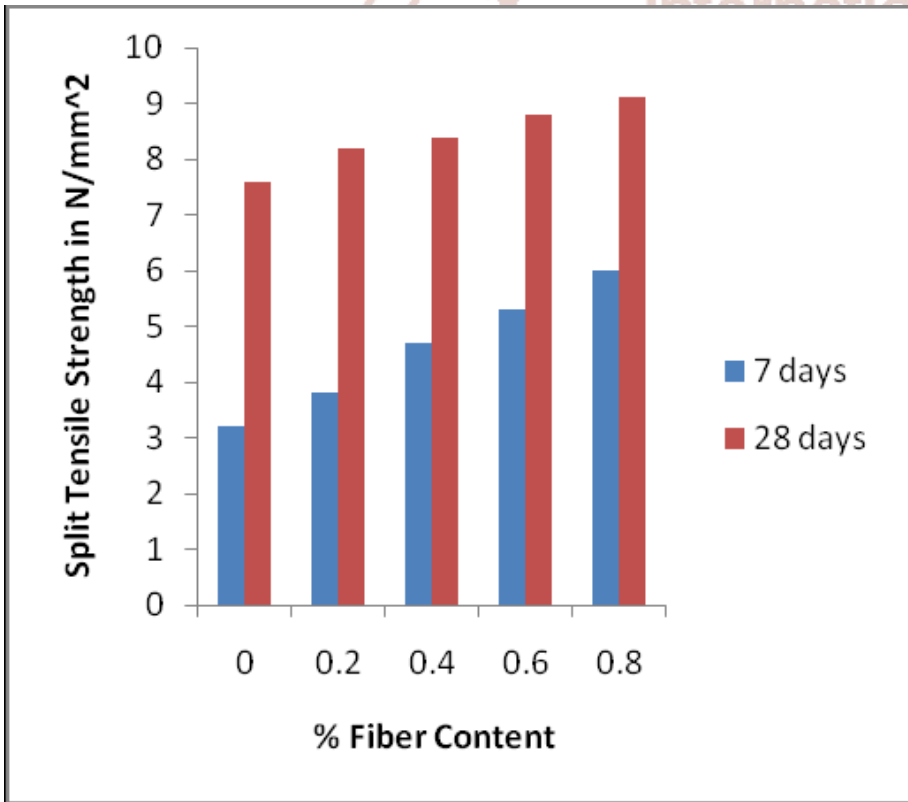

Figure 8: Split Tensile strength at different Dose of polypropylene Fiber content

\section{Conclusion}

Based on the test results the following conclusion can be drawn.

1. The inclusion of polypropylene fiber enhances the Flexural strength.

2. Maximum gain of $17 \%$ in the split tensile strength at 28 days is being observed.

3. During the investigation it was found that the PFRC has greater crack resistance because of reduction in the width of crack.

4. Workability drops down with the increase in the fiber content as there is increase in the air content due to presence of fiber.

5. Maximum increase in the flexural strength was found to be around $45 \%$ as compared to the controlled mix.

6. Result shows that there is no significant increase in the compressive strength with the increase in the fiber content.

\section{REFERENCES}

1. Priti A. Patel, Dr. Atul K. Desai and Dr. Jatin A. Desai, "Evaluation of Engineering properties for Polypropylene fiber reinforced concrete," International Journal of Advanced Engineering Technology, IJAET/Vol.III/ Issue I/JanuaryMarch, 2012/42-45.

2. Arkan Radi Ali, "Polypropylene fibers potentials in the Iraqi cementitious concrete construction," SAVAP International, ISSN-1: 2223-9553, ISSN: 2223-9944 vol. 4 no. 1 January 2013.

3. Song P. S., Hwang S., and Sheu B. C., Strength properties of nylon-and polypropylene-fiber reinforced concretes, Cement And Concrete Research, 2005; 35:1546-1550

4. 4.Alhozaimy A. M., Soroushian P., and Mirza F.,"Mechanical properties of polypropylene fiber reinforced concrete and the effects of pozzolanic materials", Cement and Concrete Composites, 1996; 18: 85-92 
5. Zollo RF. Fiber-reinforced Concrete, an Overview after 30 Years of Development. Cement and Concrete Composites 1997; 19:107- 122.

6. Abhishek kumar singh.,Anshul Jain., and Dapendra Singh, "Evaluation of Mechanical Properties for Polypropylene and Steel fiber reinforced concrete, "International Journal of Engineering Research and Technology, IJERT/Vol.II/Issue IV/April,2013/1507-1517.

7. Gao J., Sun W., and Morino K., Mechanical properties of steel fiber reinforced, high strengthlightweight concrete, Cem. Concr.Compos. 1997; 19 (4): 307-313.

8. T. Aly, J. G. Sanjayan and F. Collins, "Effect of polypropylene fibers on shrinkage and cracking of concretes," RILEM, Materials and Structures (2008) 41:1741-1753 DOI 10.1617/s11527-0089361-2.

9. Piti Sukontasukkul, "Toughness valuation of Steel and Polypropylene Fiber Reinforced Concrete Beams under Bending," Thammasat Int. J. Sc. Tech., Vol. 9, No. 3, July-September 2004.

10. Faisal Fouad Wafa, "Properties and Applications of Fiber Reinforced Concrete," JKAU: Eng. Sci., Vol. 2, 49-63(1990).
11. Tanyildizi H., " Statistical analysis for mechanical properties of polypropylene fiber reinforced lightweight concrete containing silica fume exposed to high temperature" , Materials and Design, 2009;30: 3252-3258.

12. ACI Comitte544, "Measurement of properties of Fiber Reinforced Concrete".

13. Banthia, N., and Sheng, J., "Fracture Toughness of Micro fiber Reinforced Cement Composites", Cement and Concrete Composites, Vol.18,1996,251-269.

14. Roohollah Bagherzadeh, Ph.D, Hamid Reza Pakravan, Abdol-Hossein Sadeghi, Masoud Latifi, Ali Akbar Merati, "An Investigation on Adding Polypropylene Fibers to Reinforce Lightweight Cement Composites (LWC)," Journal of Engineered Fibers and Fabrics, Volume 7, Issue 4,2012.

15. S.P. Singh, A.P. Singh and V. Bajaj, "Strength and Flexural Toughness of Concrete Reinforced with Steel - Polypropylene Hybrid Fibers," Asian journal of civil engineering (building and housing) VOL. 11, Issue 4, 495-507(2010). 